\title{
Coronavirus: Update Related to the Current Outbreak of COVID-19
}

Giovanni Gabutti · Erica d'Anchera · Federica Sandri •

Marta Savio · Armando Stefanati

Received: February 28, 2020 / Published online: April 8, 2020

(C) The Author(s) 2020

\section{ABSTRACT}

In December 2019, some cases of viral pneumonia were epidemiologically related to a new coronavirus in the province of Hubei, China. Subsequently, there has been an increase in infections attributable to this virus throughout China and worldwide. The World Health Organization (WHO) has officially named the infection coronavirus disease 2019 (COVID-19), and the virus has been classified as severe acute respiratory syndrome coronavirus 2 (SARS-CoV2). This appears to be a virus from Rhinolophus

Digital Features To view digital features for this article go to https://doi.org/10.6084/m9.figshare.11994465.

G. Gabutti $(\bowtie) \cdot$ A. Stefanati

Department of Medical Sciences, University of Ferrara, Ferrara, Italy

e-mail: giovanni.gabutti@unife.it

E. d'Anchera · F. Sandri · M. Savio

Post-Graduate School of Hygiene and Preventive

Medicine, University of Ferrara, Ferrara, Italy bats, but the intermediate host has not yet been identified. The mechanism of infection of SARSCoV-2 is not yet known; it appears to have affinity for cells located in the lower airways, where it replicates. The interhuman transmission of coronaviruses mainly occurs through saliva droplets and direct and indirect contact via surfaces. As of March 10, 2020, the number of cases worldwide was 113,702. Along with severe acute respiratory syndrome (SARS) and Middle Eastern respiratory syndrome (MERS), COVID-19 appears to cause a severe clinical picture in humans, ranging from mild malaise to death by sepsis/acute respiratory distress syndrome. The prognosis is worse in elderly patients with comorbidities. To date, there is no specific therapy for COVID-19. Prevention of SARS-CoV-2 infection implies strategies that limit the spread of the virus. WHO and other international and national bodies have developed continuously updated strategic objectives and provisions to contain the spread of the virus and infection.

Keywords: Coronavirus; COVID-19; Infectious disease; MERS; Pneumonia; Public health; SARS; SARS-COV-2 


\section{Key Summary Points}

In December 2019, some cases of viral pneumonia in China were associated with a new coronavirus, which subsequently spread worldwide. WHO has officially named the infection COVID-19, and the virus has been classified as SARS-CoV-2.

The infection has three worsening clinical pictures: at the onset a mild malaise with symptoms of the upper respiratory tract, subsequently a mild pneumonia, which can later worsen with a picture of acute respiratory distress.

Early recognition of the clinical picture is essential to be able to start the correct preventive measures and supportive treatments in a short time to avoid possible complications in patients. A combination of public health measures, such as rapid identification, diagnosis and case management, identification and follow-up of contacts, and prevention and control of infections in healthcare facilities, is essential for preventive purposes; also implementation of health measures for travelers, awareness raising in the population and risk communication are important.

As of March 10, 2020, the number of confirmed cases worldwide was 113,702. According to the ECDC, the CFR for hospitalized COVID-19 cases is $4 \%$ and the R0 is estimated between 2 and 3 .

Currently, there are many uncertainties about the origin of the virus, the extent and duration of transmission in humans, the ability to infect other animal hosts and the pathogenesis of human infections. The data collected to date are essential for understanding the threat posed by SARS-CoV-2.

\section{BACKGROUND}

Coronaviruses (CoVs) are a large family of respiratory viruses that can cause mild to moderate diseases, ranging from the common cold to severe respiratory syndromes [1].

These viruses are common in many animal species, and, in some cases, albeit rarely, they can evolve and infect humans and then spread to the population [2].

Most of the numerous human pathogenic coronaviruses are associated with mild clinical symptoms, with two notable exceptions: severe acute respiratory syndrome (SARS) and Middle East respiratory syndrome (MERS). SARS is caused by a virus that emerged in southern China in November 2002 and led to $>8000$ human infections and 774 deaths in 37 countries in the 2002-2003 period [3]; MERS is related to a virus detected for the first time in Saudi Arabia in 2012, responsible for 2494 laboratoryconfirmed cases of infection and 858 deaths since September 2012 [4].

In December 2019, some cases of viral pneumonia were epidemiologically linked to a new coronavirus in the province of Hubei in China. In the following days a possible association with the Huanan fish market in Wuhan was identified. In fact, most of the initially identified patients had visited, worked at or lived near this market in the month preceding the infection. In early January, a new coronavirus, tentatively called $2019-\mathrm{nCoV}$, was isolated, and interhuman transmission was confirmed [5].

On February 11, 2020, the World Health Organization (WHO) officially named the new coronavirus 2019 infection Coronavirus Disease 2019 (COVID-19) [6]. Subsequently the Coronavirus Study Group (CSG) of the International Taxonomy Committee of Viruses (ICTV) officially classified the virus as severe acute respiratory syndrome coronavirus 2 (SARS-CoV-2) [7]. This article is based on previously conducted studies and does not contain any studies with human participants or animals performed by any of the authors. 


\section{CORONAVIRUSES}

\section{Microbiologic Aspects}

Coronaviruses (CoVs) are RNA viruses belonging to the subfamily of the Coronavirinae, Coronaviridae family, order Nidovirales [8].

Their definition is related to the fact that CoVs are virions with projections resembling a crown. All CoVs share similarities in organization and genomic expression with 16 nonstructural proteins and at least 4 structural proteins (spike: S; envelope: E; membrane: $\mathrm{M}$; nucleocapsid: $\mathrm{N}$ proteins) [9].

They are divided into four genera: alphaCoV, betaCoV, gammaCoV and deltaCoV [10].

CoVs can infect different hosts and have a different tissue tropism: generally, alphaCoVs and betaCoVs infect mammals while gammaCoVs and deltaCoVs infect other animals such as birds, fishes and only a few mammals [8] (Table 1).

Seven human CoVs are known to date, common worldwide. The first ones were identified in the mid-1960s, others more recently [9].

The human CoVs are: 229E (alfaCoV), NL63 (alfaCoV), OC43 (betaCoV), HKU1 (betaCoV), MERS-CoV (betaCoV, which causes MERS), SARS-CoV (betaCoV, which causes SARS) and 2019-nCoV/SARS-CoV-2 [11].

\section{SARS and MERS: Epidemiology and Clinical Characteristics}

In the past 20 years, two major human CoV epidemics have occurred: SARS and MERS. Both viruses infect the lower airways and cause severe respiratory syndromes in humans. Other CoVs have a global distribution with a seasonality characterized by a peak in winter and in spring and few cases in summer [10].

The SARS epidemic began in 2002, starting from the town of Foshan in the Chinese province of Guangdong, and then spread globally, involving 33 countries in 5 different continents. More than 8000 cases were recognized $(21 \%$ in health workers) with a case fatality rate (CFR) of
Table 1 List of important pathogenic coronaviruses (modified from [8])

\begin{tabular}{|c|c|c|}
\hline Host & Genus & Virus \\
\hline \multirow[t]{6}{*}{ Human } & Alpha & Human CoV-229E \\
\hline & & Human CoV-NL63 \\
\hline & Beta & Human CoV-HKU1 \\
\hline & & Human CoV-OC43 \\
\hline & & SARS-CoV \\
\hline & & MERS-CoV \\
\hline \multirow[t]{4}{*}{ Pig } & Alpha & PRCV/ISU-1 \\
\hline & & TGEV/PUR46-MAD \\
\hline & & PEDV/ZJU-G1-2013 \\
\hline & & SeACoV-CH/GD-01 \\
\hline Dog & Alpha & Canine CoV/TU336/F/2008 \\
\hline Camel & Alpha & $\begin{array}{l}\text { Camel alphacoronavirus isolate } \\
\text { Camel/Riyadh }\end{array}$ \\
\hline Cat & Alpha & Feline infectious peritonitis virus \\
\hline Cow & Beta & Bovine $\mathrm{CoV} / \mathrm{ENT}$ \\
\hline Horse & Beta & Equine CoV/OBIHIRO12-1 \\
\hline Mice & Beta & MHV-A59 \\
\hline Chicken & Gamma & IBV \\
\hline Whale & Gamma & Beluga whale $\mathrm{CoV} / \mathrm{SW} 1$ \\
\hline Bulbul & Delta & Bulbul coronavirus HKU11 \\
\hline
\end{tabular}

almost 10\% [3] and a basic reproduction number $\left(R_{0}\right)$ equal to $2-3$ [12].

In humans, the incubation period ranges between 2 and 10 days, and interhuman transmission is very effective, which is why the delay of 3 months between the beginning of the epidemic and the first investigations has allowed a worldwide spread of the virus. The bat was identified as the natural reservoir of SARS-CoV and the civet as the intermediate host [13]. Despite active surveillance, no more SARS cases have been recognized since July 2003 [3].

MERS was first identified in 2012. From then until January 16, 2020, 2521 cases were reported worldwide. These include 919 deaths, with a 
CFR of $36 \%$ [4] and an estimated $R_{0}$ of 0.7 [12]. Most cases were found in the Arabian Peninsula and approximately $84 \%$ in Saudi Arabia [4]. However, the virus was isolated in 27 countries [10], and all patients outside the Arabian Peninsula had a travel history to or a contact with someone who had traveled to this region [4]. In humans, the incubation period ranges between 2 and 14 days, and, unlike SARS, interhuman transmission is limited. The virus is not easily transmitted from person to person, unless a close contact occurs. The bat was also identified as an animal reservoir for the MERS$\mathrm{CoV}$, while the intermediate host was the camel [13].

Both SARS and MERS have a broad spectrum of clinical pictures ranging from flu-like symptoms to acute respiratory distress syndrome (ARDS). Age and comorbidities are prognostic predictors. SARS mainly involved healthy young adults while half of MERS cases were identified in subjects $>50$ years of age. The clinical picture at hospital admission is characterized by fever, cough, dyspnea and myalgia in both SARS and MERS. Atypical symptoms such as diarrhea and vomiting are common in both syndromes [10].

\section{THE CURRENT OUTBREAK OF COVID-19}

\section{Epidemiology}

On December 31, 2019, the WHO Chinese Office was informed about some cases of pneumonia of unknown origin in the city of Wuhan, located in the Chinese province of Hubei [14].

On January 3, 2020, a new coronavirus was isolated from the bronchial wash samples of a patient from Wuhan and was identified as the pathogen responsible for pneumonia [15]. On January 11 and 12, 2020, the WHO received further details and information from the Chinese National Health Commission regarding the possible association of this epidemic with exposure in a fish market in Wuhan, and the Chinese authorities shared the genetic sequence of a new coronavirus, subsequently identified as SARSCoV-2 [14].
New evidence shows the relation between SARS-CoV-2 and other CoVs that are circulating in bats, specifically in Rhinolophus bats [16]. These subspecies are abundant in southern China and Asia, the Middle East, Africa and Europe. The mode of transmission to humans is still unclear. Bats are rare in Chinese markets; however, they are captured and sold directly to restaurants as food. The most recent hypothesis is that there is an intermediate animal host that has played a role in the new SARS-CoV-2 infection [6]. Several animals have been considered as possible hosts, including pangolins [17]. Identifying the animal source of this new virus would help to prevent other new infections and to understand the initial dynamics of spreading in the Wuhan market. In this regard, strengthening the control of food and hygiene within live animal markets is essential to prevent future new zoonosis [6].

The mechanism of SARS-CoV-2 infection is not yet known. The key to human transmission is the ability of the virus to bind to human cells: CoVs use the spike protein to bind to cells, and it seems that SARS-CoV-2, as SARS-Co virus, uses the same receptor for the conversion enzyme of angiotensin 2 (ACE2) $[5,13]$. A recent study showed that the binding affinity between the viral receptorbinding domain (RBD) and the host receptor ACE2, in the initial viral attachment step, determines the host susceptibility to SARS-CoV-2. The greater transmissibility of SARS-CoV-2 than SARS$\mathrm{CoV}$ is partly explained by the fact that, due to a higher affinity, the binding capacity of viral RBD increases and the number of viruses required to infect a cell is reduced [18]. SARS-CoV-2 appears to have affinity for cells located in the lower airways, where it replicates, causing radiologic evidence of pneumonia in patients without any particular clinical symptoms [19].

Usually, the interhuman transmission of CoVs occurs through different pathways that include droplets, direct contact and indirect contact through surfaces [13]. The virus has also been isolated in serum, blood, rectal swabs, saliva, urine and stool [18]. Fecal-oral transmission has not yet been proven $[20,21]$.

A recent study indicates that the highest viral load is found immediately after the onset of symptoms and in greater quantities in the nose rather than in the throat. This analysis 
suggests that the spread of the SARS-CoV-2 virus resembles that of influenza more than that of SARS. The viral load found in asymptomatic subjects was similar to that of symptomatic ones; this suggests the potential transmission role of asymptomatic subjects [22].

Despite several uncertainties, the evidence indicates that the CFR for hospitalized COVID19 patients is substantially lower than that for hospitalized SARS, MERS and 2009 pandemic flu H1N1 patients $(4 \%, 28 \%, 65 \%$ and $9 \%$, respectively). Taking into account COVID-19 and influenza (pandemic and seasonal), it is important to carefully consider the differences in definition of cases, as these are relevant for CFR estimation [18].

The $R_{0}$ has been estimated between 2 and 3 [18], and the risk assessment calculated by WHO is very high for the whole world [23].

As of March 10, 2020, there were 113,702 confirmed cases of SARS-CoV-2 infection in the world, with 4125 new cases in the last $24 \mathrm{~h}$. In China, the country with the highest number of confirmed cases, 80,924 occurred, of which 20 were within $24 \mathrm{~h}$ with 3140 total deaths (17 new in the last $24 \mathrm{~h}$ ) [23].

The first case of SARS-CoV-2 laboratory-confirmed infection outside China was reported on January 13, 2020, in Thailand [14].

As of March 10, 2020, outside China there were 32,778 confirmed cases and 872 deaths, and 109 countries were involved [23]. In the Western Pacific region, the countries with the highest number of cases were Republic of Korea (7513), Japan (514) and Singapore (160) [23].

In the European Region, Italy counted 9172 cases; thus it was the second country with the most cases after China. France, Germany and Spain reported 1402, 1139 and 1024 cases, respectively, while another 44 countries reported $<400$ cases [23]. In the Eastern Mediterranean Region, Iran was the country with the highest number of cases (7161) [23]. In the USA, 472 cases were reported [23].

Of note, 696 cases, including 7 deaths, were reported in subjects on a cruise ship that had been anchored in Japanese territorial waters [23].

\section{Clinical Aspects}

Several clinical pictures have been associated with SARS-CoV-2 infection; they range from mild malaise to death, which occurs from sepsis and/or ARDS.

Early recognition of the clinical picture is essential to promptly start the adequate preventive measures and supportive treatments to avoid spreading of the virus and possible complications in patients [19] (Table 2).

It seems that COVID-19 presents with three worsening clinical pictures that evolve in few days: at the onset a slight malaise with symptoms of the upper respiratory tract, subsequently a mild pneumonia that can later worsen with a picture of ARDS [19].

Several retrospective studies show that hospitalization generally takes place on the 7 th day after the onset of the symptoms (fever, fatigue and dry cough with dyspnea) [1, 15].

Other possible symptoms are myalgia, headache, anorexia, pharyngodynia and gastrointestinal complaints with diarrhea. Many patients developed multiorgan dysfunction, radiologic signs of bilateral pneumonia with ARDS and acute renal failure; furthermore, mental confusion may occur [15]. The incubation period lasts up to 14 days (4-5 days as median incubation period) $[12,18]$.

Recently, the Chinese Center for Disease Control and Prevention (CCDC) has published a work on a series of cases, currently the most numerous in the literature, concerning mainland China (updated on February 11, 2020). Healthcare workers represent $3.8 \%$ of cases; $14.8 \%$ of these have been confirmed as serious or critical cases [24, 25].

As for the distribution by age, $1 \%, 8 \%$ and $87 \%$ of cases were registered in young subjects ( $<10$ years and between 10 and 19 years of age), young adults (aged between 20 and 29 years) and adults and elderly people (age range 30-79 years), respectively. Elderly patients aged $\geq 80$ years represented $3 \%$ of cases. Regarding the spectrum of the disease, $81 \%$, $14 \%$ and $5 \%$ of cases were affected by a medium intensity, severe and critical form, respectively [24, 25] (Table 3). 
Table 2 Definition of cases of SARS-CoV-2 infection (modified from [23])

\begin{tabular}{|c|c|}
\hline \multirow[t]{10}{*}{$\begin{array}{l}\text { Suspected case of } \\
\text { COVID-19 }\end{array}$} & $\begin{array}{l}\text { A patient with acute respiratory illness (fever and at least one sign/symptom of respiratory disease, } \\
\text { e.g., cough, shortness of breath) }\end{array}$ \\
\hline & AND with no other etiology that fully explains the clinical presentation \\
\hline & $\begin{array}{l}\text { AND a history of travel to or residence in a country/area or territory reporting local transmission } \\
\text { of COVID-19 disease during the } 14 \text { days prior to symptom onset }\end{array}$ \\
\hline & OR \\
\hline & A patient with any acute respiratory illness \\
\hline & $\begin{array}{l}\text { AND having been in contact with a confirmed or probable COVID-19 case in the last } 14 \text { days } \\
\text { prior to onset of symptoms }\end{array}$ \\
\hline & OR \\
\hline & $\begin{array}{l}\text { A patient with severe acute respiratory infection (fever and at least one sign/symptom of } \\
\text { respiratory disease, e.g., cough, shortness of breath) }\end{array}$ \\
\hline & AND requiring hospitalization \\
\hline & AND with no other etiology that fully explains the clinical presentation \\
\hline Probable case & A suspect case for whom testing for COVID-19 is inconclusive \\
\hline Confirmed case & $\begin{array}{l}\text { A person with laboratory confirmation of COVID-19 infection, irrespective of clinical signs and } \\
\text { symptoms }\end{array}$ \\
\hline
\end{tabular}

According to these data, the overall CFR rate is $2.3 \%$. In detail, CFR was equal to $8 \%$ and $14.8 \%$ in subjects aged between 70 and 79 years and in patients aged $\geq 80$ years, respectively. No subject $<9$ years of age died. No deaths have been registered in subjects suffering from mild or medium intensity forms, while CFR was equal to $49 \%$ in critical cases [24, 25] (Table 3).

Notably, CFR was high in subjects with comorbidities; in detail, CFR was equal to $10.5 \%, 7.3 \%, 6.3 \%, 6.0 \%$ and $5.6 \%$ for cardiovascular diseases, diabetes, chronic respiratory diseases, hypertension and tumors, respectively [24, 25] (Table 3).

In conclusion people $>60$ years of age and patients with comorbidities (most of all cardiovascular diseases) have a greater risk for a more severe clinical picture and for fatal outcome. Furthermore, deaths occurred only in critical cases. Fortunately, COVID-19 seems to be relatively rare in children, whose clinical picture is often mild [18].
According to another Chinese study, the median age of patients is 56 years, with a slightly higher percentage in males (54.3\% males vs. $45.7 \%$ females). Intensive care unit (ICU) admission was needed in $26 \%$ of subjects, and $4.3 \%$ of them died of multiorgan failure. Once more, the worst clinical pictures refer to elderly subjects with comorbidities such as diabetes, high blood pressure and cardiovascular diseases [15].

Inter-human transmission was considered for $41 \%$ of patients: the infection seems related to previous exposure to the Huanan fish market in $8.7 \%$ of cases, family members in $12.3 \%$ and healthcare workers in 29\% [15].

According to another study, some cases have also been reported in children aged 111 months: the clinical picture was less severe than in adults, with fever and mild respiratory infections as prevalent symptoms. The transmission was mainly intra-familiar or through contacts with visitors to the Huanan market [26]. 
Table 3 Key findings from the Chinese Center for Disease Control and Prevention report (modified from [24, 25])

\begin{tabular}{|c|c|c|c|c|}
\hline Baseline characteristics & Confirmed cases, $N(\%)$ & Deaths, $N(\%)$ & Case fatality rate, $\%$ & Observed time, PD \\
\hline Overall & 44,672 & 1023 & 2.3 & 661,609 \\
\hline \multicolumn{5}{|l|}{ Age, years } \\
\hline $0-9$ & $416(0.9)$ & - & - & 4383 \\
\hline $10-19$ & $549(1.2)$ & $1(0.1)$ & 0.2 & 6625 \\
\hline $20-29$ & $3619(8.1)$ & $7(0.7)$ & 0.2 & 53,953 \\
\hline $30-39$ & $7600(17.0)$ & $18(1.8)$ & 0.2 & 114,550 \\
\hline $40-49$ & $8571(19.2)$ & $38(3.7)$ & 0.4 & 128,448 \\
\hline $50-59$ & $10,008(22.4)$ & $130(12.7)$ & 1.3 & 151,059 \\
\hline $60-69$ & $8583(19.2)$ & $309(30.2)$ & 3.6 & 128,088 \\
\hline $70-79$ & $3918(8.8)$ & $312(30.5)$ & 8.0 & 55,832 \\
\hline$\geq 80$ & $1408(3.2)$ & $208(20.3)$ & 14.8 & 18,671 \\
\hline \multicolumn{5}{|l|}{ Sex } \\
\hline Male & $22,981(51.4)$ & $653(63.8)$ & 2.8 & 342,063 \\
\hline Female & $21,691(48.6)$ & $370(36.2)$ & 1.7 & 319,546 \\
\hline \multicolumn{5}{|l|}{ Comorbidity condition $^{a}$} \\
\hline Hypertension & $2683(12.8)$ & $161(39.7)$ & 6.0 & 42,603 \\
\hline Diabetes & $1102(5.3)$ & $80(19.7)$ & 7.3 & 17,940 \\
\hline Cardiovascular disease & $873(4.2)$ & $92(22.7)$ & 10.5 & 13,533 \\
\hline Chronic respiratory disease & $511(2.4)$ & $32(7.9)$ & 6.3 & 8083 \\
\hline Cancer (any) & $107(0.5)$ & $6(1.5)$ & 5.6 & 1690 \\
\hline None & $15,536(74.0)$ & $133(32.8)$ & 0.9 & 242,948 \\
\hline Missing & $23,690(53.0)$ & $617(60.3)$ & 2.6 & 331,843 \\
\hline \multicolumn{5}{|l|}{ Case severity $^{\mathrm{b}}$} \\
\hline Mild & $36,160(80.9)$ & - & - & - \\
\hline Severe & $6168(13.8)$ & - & - & - \\
\hline Critical & $2087(4.7)$ & $1023(100)$ & 49.0 & 31,456 \\
\hline Missing & $257(0.6)$ & - & - & - \\
\hline
\end{tabular}

$P D$ person-days, - not applicable

a The comorbidity condition variable only includes a total of 20,812 patients and 504 deaths, and these values were used to calculate percentages in the confirmed cases and deaths columns

b The case severity variable only includes a total of 44,415 patients and 1023 deaths, and these values were used to calculate percentages in the confirmed cases and deaths columns 
A recent study analyzed nine pregnant women with SARS-CoV-2 pneumonia. Their clinical picture was similar to that of nonpregnant women affected by the virus. In all cases, a cesarean delivery was done, and no vertical transmission has been documented. Therefore, it can be assumed that there is no evidence of vertical transmission during the third trimester of pregnancy [27].

\section{Diagnosis, Therapy and Prevention}

The diagnosis and confirmation of SARS-CoV-2 infection are carried out by specific tests recommended by WHO that are described on a dedicated webpage [28].

The European Centre for Disease Prevention and Control (ECDC) also provided a specific webpage on laboratory support by a coronavirus-specialized laboratory in the European Union [29].

Any person satisfying the criteria of a suspected case (Table 2) should be tested for SARSCoV-2, and, when possible, samples from both the lower respiratory tract (bronchoalveolar lavage, endotracheal aspirate, expectorated sputum) and upper respiratory tract (nasopharyngeal swab, oropharyngeal swab, nasopharyngeal aspirate or nasal wash) should be collected [29].

According to a recent Chinese study, collecting specimens from different sites could be useful to improve the sensitivity and reduce false-negative test results. This study highlights that bronchoalveolar lavage fluid specimens showed the highest positive rates, followed by sputum, nasal swabs, bronchial biopsy, pharyngeal swabs, feces and blood [30].

To date, there is no specific therapy for COVID-19. Patients with COVID-19 should receive supportive care to help relieve symptoms, and, for severe cases, treatment should include care to support vital organ functions [31, 32].

Several randomized clinical trials (RCTs) are currently underway, not yet published, which are testing different therapies for COVID-19. One of the drugs, normally used in the treatment of rheumatoid arthritis, targets the interleukin 6 receptor and has been included in the COVID-19 treatment guidelines issued by the Chinese National Health Commission $[33,34]$. In addition, several RCTs are underway regarding the use of antiviral drugs for the treatment of COVID-19 [32, 35-38]. Finally, a recent study evaluates the use of plasma from convalescent patients with previous SARS-CoV2 infection as a potential therapeutic treatment [39]. Another study shows that the use of systemic corticosteroids for COVID-19 is not recommended [40].

\section{Public Health Impact}

The advent of COVID-19 is unquestionably reminiscent of previous SARS and MERS epidemics. The increase in the number of cases and expansion of geographical areas have revealed issues regarding the future management of the infection: on March 11, 2020, the WHO declared COVID-19 a pandemic [41].

At the beginning, efforts were made by the Chinese government to limit the spread of the virus, such as suspension of public transport, closure of airports [42], cancellation of the Lunar New Year celebrations and closure of parks and cinemas. A ban on the wild animal trade within China was declared on January 26, 2020 [12]. As the number of cases increased, more drastic containment measures were applied in China up to the suspension of all non-essential activities. These measures appear to have slowed the progression of SARS-CoV-2 infections in China, as can be seen from the progressive decrease in incidence in Wuhan [23].

Since the beginning, the $\mathrm{WHO}$ and the Emergency Committee under International Health Regulations have stressed China's need to strengthen screening of exits from affected areas. In general, evidence in the peer-reviewed literature does not support entry screening as an effective measure for detecting infected travelers, especially when symptoms of the disease are very common/aspecific and the seasonal flu activity in Europe and China is ongoing. However, some imported cases of COVID-19 in Asian countries have been detected through 
entry screening procedures at the destination airports [12].

One of the screening methods for COVID-19 is the measurement of body temperature, although current evidence shows that this method is not effective in controlling disease transmission [18].

As of March 10, 2020, WHO believes that restrictive measures for travelers and the exchange of goods must be proportional to the risk to public health, with the minimum duration possible and daily updates accordingly on the available epidemiology [43].

Currently, the US Centers for Disease Control and Prevention (CDC) has increased the level of traveler health alert and recommends avoiding non-essential travel [44]. Other countries are considering implementing restrictions for people traveling from and to the most affected countries.

Since the beginning of the pandemic, the WHO has developed a strategy and response plan to contain the impact of COVID-19. The main points included in this plan are related to blocking the chain of transmission (working on patients as well as close contacts), identifying and reducing transmission from animal sources, developing correct and scientifically sound risk communication and controlling the social and economic impact of the pandemic as much as possible to minimize it through multisectoral partnerships [6].

The ECDC, taking into account the evolving epidemiologic situation, considers five possible scenarios (from 0 to 4 ). The objective is to avoid the health system disruption and to limit the impact of the pandemic as much as possible [18] (Table 4).

Crucial general preventive measures should include: rigorous hand hygiene, avoiding coughing and/or sneezing without covering the mouth and the use of disposable tissues to mechanically block droplets [18]. The WHO recommends hand washing with soap and water or use of alcohol-based solutions [45].

The use of surgical face masks can reduce the risk of infection transmission; masks should be used by subjects with respiratory symptoms. There is no evidence of the usefulness of face masks by healthy subjects; besides, their use can be related to an increased risk due to a false sense of safety [18].

Isolation of symptomatic subjects can be considered to reduce transmission; patients (suspected or confirmed) should be asked to wear a surgical mask to reduce the spread of

Table 4 Different scenarios and options to limit the impact of the epidemic (modified from [18])

\begin{tabular}{cll}
\hline Scenarios & Characterization & Risk management and options for response \\
\hline $\begin{array}{c}\text { Scenario } \\
0\end{array}$ & No case & $\begin{array}{c}\text { Rapid identification of individual cases and } \\
\text { prevention of domestic transmission }\end{array}$ \\
$\begin{array}{ccc}\text { Scenario } \\
1\end{array}$ & $\begin{array}{c}\text { Some imported cases and local transmission with } \\
\text { epidemiologic identification }\end{array}$ & $\begin{array}{c}\text { Prevent transmission where possible and slow the } \\
\text { progression of infection }\end{array}$ \\
$\begin{array}{c}\text { Scenario } \\
2\end{array}$ & $\begin{array}{c}\text { Increase in imported cases and more than two } \\
\text { generations of cases with inter-human transmission } \\
\text { within the country with epidemiologic identification }\end{array}$ & $\begin{array}{c}\text { Strengthen the health system, protect the population } \\
\text { most at risk, increase the availability of airborne } \\
\text { transmission precautions (PPE) and diagnostic } \\
\text { tests }\end{array}$ \\
$\begin{array}{c}\text { Scenario } \\
4\end{array}$ & $\begin{array}{c}\text { Localized outbreaks, which start to merge, becoming } \\
\text { epidemiologically indistinct }\end{array}$ & $\begin{array}{c}\text { Reduce burden on the health system and protect the } \\
\text { population at risk }\end{array}$ \\
& $\begin{array}{c}\text { system over-burdened because of the large demand for } \\
\text { services }\end{array}$ & $\begin{array}{c}\text { Mitigate the impact of dissemination, protect the } \\
\text { population at risk and reduce excessive mortality }\end{array}$ \\
\hline
\end{tabular}


respiratory droplets, considered the most likely route of transmission [18].

Currently, many countries are considering or have already implemented relevant social measures such as school closures, smart working and cancelling meetings, sports and cultural events. Social distancing is essential. It implies avoiding shaking hands and kissing, use of public and crowded means of transportation, and gatherings of people [18].

Strict compliance with all these measures is essential to lower the spread of infection to gain time to identify adequate therapeutic options and to design and hopefully develop a vaccine [18].

Italy is now the second country in the world in terms of case numbers [23]. The first cases occurred in some areas of Lombardy and the Veneto regions and then spread all over the country. As of March 9, 2020, considering that new cases of COVID-19 registered in Italy had started to increase considerably and national restrictive measures had not yet been put in place, the Council of Ministers issued a decree law with measures to prohibit access to and exit from the country as well as suspension of all the activities that were not strictly necessary $[46,47]$.

The current Italian situation confirms that a local outbreak, once started, can quickly spread and have a huge impact on the most vulnerable citizens, mainly elderly subjects with comorbidities [18]. Although to date no SARS-CoV-2 bloodborne transmission has been documented, the National Blood Center of the National Institute of Health (ISS) has activated precautionary measures to prevent the spread of the new coronavirus SARS-CoV-2 from blood donors [48].

ECDC reports that, as of March 2, 2020, the risk of COVID-19 infection in Europe is currently moderate to high and can change. It should be considered that the transmission chain has not always been identified and that the epidemiologic situation is constantly evolving [18].

\section{CONCLUSIONS}

The spread of the SARS-CoV-2 virus represents a global health emergency involving the health authorities of all countries, especially since the pandemic state was declared.

Many aspects of the infection have been studied. Available epidemiologic, clinical and impact data have made it possible to outline preventive interventions that have been shared internationally. Unfortunately, the spread of the virus is ongoing, and the impact of the infection is still growing, despite the application of preventive interventions, which in some contexts are very restrictive. The impact of the infection is evident not only from a clinical but also from an economic point of view.

The considerable cost in terms of infected/ dead health workers, who operate on the front line and, as such, are particularly exposed to the risk of infection, should not be underestimated [25].

Strict observance of the rules issued by the WHO and the other international bodies (e.g., CDC, ECDC, etc.) is essential, as we need to understand the dynamics of virus spread in more detail, identify new diagnostic and therapeutic approaches and develop a vaccine reasonably quickly. The international effort is enormous and hopefully will allow preventing further spreading of the virus [42].

\section{ACKNOWLEDGEMENTS}

Epidemiologic daily updated cases can be found on the following web pages: https://www.who. int/emergencies/diseases/novel-coronavirus-2019/ >situation-reports/. https://www.ecdc.europa.eu/ en/novel-coronavirus-china.

Funding. No funding or sponsorship was received for this study or publication of this article.

Authorship. All named authors meet the International Committee of Medical Journal Editors (ICMJE) criteria for authorship for this article, take responsibility for the integrity of 
the work as a whole and have given their approval for this version to be published.

Disclosures. Erica d'Anchera, Federica Sandri, Marta Savio and Armando Stefanati declare that they have no conflict of interest. Giovanni Gabutti declares that he does not have a specific conflict of interest related to this paper; however, he reports grants from Sanofi Pasteur MSD, GSK Biologicals SA, Pfizer, Sanofi Pasteur Italy, MSD Italy, Emergent BioSolutions and Seqirus for taking part to advisory boards, expert meetings, for acting as speaker and/or organizer of meetings/congresses and as principal investigator and chief of O.U. in RCTs.

Compliance with Ethics Guidelines. This article is based on previously conducted studies and does not contain any studies with human participants or animals performed by any of the authors.

Data Availability. Data sharing is not applicable to this article as no datasets were generated or analyzed during the current study.

Open Access. This article is licensed under a Creative Commons Attribution-NonCommercial 4.0 International License, which permits any non-commercial use, sharing, adaptation, distribution and reproduction in any medium or format, as long as you give appropriate credit to the original author(s) and the source, provide a link to the Creative Commons licence, and indicate if changes were made. The images or other third party material in this article are included in the article's Creative Commons licence, unless indicated otherwise in a credit line to the material. If material is not included in the article's Creative Commons licence and your intended use is not permitted by statutory regulation or exceeds the permitted use, you will need to obtain permission directly from the copyright holder. To view a copy of this licence, visit http://creativecommons.org/licenses/by$\mathrm{nc} / 4.0 /$.

\section{REFERENCES}

1. Chen N, Zhou M, Dong X, et al. Epidemiological and clinical characteristics of 99 cases of 2019 novel coronavirus pneumonia in Wuhan, China: a descriptive study. Lancet. 2020;395:507-13.

2. ISS. Focolaio di infezione da un nuovo coronavirus (2019-nCoV). https://www.epicentro.iss.it/ coronavirus/2019-nCoV. Accessed 10 Feb 2020.

3. ECDC. Severe acute respiratory syndrome (SARS). 2016. https://www.ecdc.europa.eu/sites/default/ files/documents/AER_for_2015-SARS.pdf. Accessed 12 Feb 2020.

4. ECDC. Risk assessment guidelines for infectious diseases transmitted on aircraft (RAGIDA) Middle East Respiratory Syndrome Coronavirus (MERS-CoV). 2020. https://www.ecdc.europa.eu/sites/default/ files/documents/infectious-diseases-transmittedon-aircrafts-ragida-risk-assessment-guidelines.pdf. Accessed 12 Feb 2020.

5. Lu R, Zhao X, Li J, et al. Genomic characterisation and epidemiology of 2019 novel coronavirus: implications for virus origins and receptor binding. Lancet. 2020;395:565-74.

6. WHO. Novel Coronavirus (2019-nCoV) Situation Report-22. https://www.who.int/docs/defaultsource/coronaviruse/situation-reports/20200211sitrep-22-ncov.pdf?sfvrsn=fb6d49b1_2. Accessed 12 Feb 2020.

7. ISS. Focolaio di infezione da nuovo coronavirus SARS-CoV-2. https://www.epicentro.iss.it/ coronavirus/2019-nCoV. Accessed 20 Feb 2020.

8. Chen Y, Liu Q, Guo D. Emerging coronaviruses: genome structure, replication, and pathogenesis. J Med Virol. 2020;92(4):418-23.

9. Su S, Wong G, Shi W, et al. Epidemiology, genetic recombination, and pathogenesis of coronaviruses. Trends Microbiol. 2016;24(6):490-502.

10. Yin Y, Wunderink RG. MERS, SARS and other coronaviruses as causes of pneumonia. Respirology. 2018;23(2):130-7.

11. ISS. Coronavirus: news. https://www.epicentro.iss. it/coronavirus/aggiornamenti. Accessed 30 Jan 2020 .

12. ECDC. Outbreak of acute respiratory syndrome associated with a novel coronavirus, China: first local transmission in the EU/EEA-third update. https://www.ecdc.europa.eu/sites/default/ files/documents/novel-coronavirus-risk-assessmentchina-31-january-2020_0.pdf. Accessed 12 Feb 2020. 
13. Lee P-I, Hsueh P-R. Emerging threats from zoonotic coronaviruses-from SARS and MERS to 2019-nCoV. J Microbiol Immunol Infect. 2020. https://doi.org/ 10.1016/j.jmii.2020.02.001.

14. WHO. Novel Coronavirus (2019-nCoV) Situation report-1. https://www.who.int/docs/defaultsource/coronaviruse/situation-reports/20200121sitrep-1-2019-ncov.pdf?sfvrsn=20a99c10_4. Accessed 14 Feb 2020.

15. Wang D, Hu B, Hu C, et al. Clinical Characteristics of 138 Hospitalized Patients With 2019 Novel Coronavirus-Infected Pneumonia in Wuhan, China. JAMA. 2020;323(11):1061-69. https://doi. org/10.1001/jama.2020.1585.

16. Benvenuto D, Giovannetti M, Ciccozzi A, Spoto S, Angeletti S, Ciccozzi M. The 2019-new coronavirus epidemic: evidence for virus evolution. J Med Virol. 2020. https://doi.org/10.1101/2020.01.24.915157.

17. Zhang H, Penninger JM, Li Y, Zhong N, Slutsky AS. Angiotensin-converting enzyme 2 (ACE2) as a SARS-CoV-2 receptor: molecular mechanisms and potential therapeutic target. Intensive Care Med. 2020;46(4):586-90.

18. ECDC. Outbreak of novel coronavirus disease 2019 (COVID-19): increased transmission globally-fifth update. https://www.ecdc.europa.eu/sites/default/ files/documents/RRA-outbreak-novel-coronavirusdisease-2019-increase-transmission-globally-COVID19.pdf. Accessed 11 Mar 2020.

19. Heymann DL, Shindo N, Scientific W, Advisory Group for Infectious Hazards T. Comment COVID19: what is next for public health? Lancet. 2020;392:542-5.

20. Holshue ML, DeBolt C, Lindquist S, et al. First Case of 2019 Novel Coronavirus in the United States. N Engl J Med. 2020;382(10):929-36.

21. Zhang H, Kang Z, Gong $\mathrm{H}$ et al. The digestive system is a potential route of 2019-nCov infection: a bioinformatics analysis based on single-cell transcriptomes. bioRxiv. 2020. https://doi.org/10.1101/ 2020.01.30.927806.

22. Zou L, Ruan F, Huang $M$ et al. SARS-CoV-2 viral load in upper respiratory specimens of infected patients. N Engl J Med. 2020. NEJMc2001737. https://www.nejm.org/doi/10.1056/

NEJMc2001737. Accessed 21 Feb 2020.

23. WHO. Situation Report-50 Situation in numbers total and new cases in last 24 hours. https://www. who.int/docs/default-source/coronaviruse/situationreports/20200310-sitrep-50-covid-19.pdf?sfvrsn $=55 \mathrm{e}$ 904fb_2. Accessed 11 Mar 2020.
24. Wu Z, McGoogan JM. Characteristics of and important lessons from the coronavirus disease 2019 (COVID-19) outbreak in China: summary of a report of 72,314 cases from the Chinese Center for Disease Control and Prevention. JAMA. 2020;2019: 24-7.

25. CCDC. The epidemiological characteristics of an outbreak of 2019 Novel Coronavirus Diseases (COVID-19)—China. $2020 . \quad$ https://weekly. chinacdc.cn/en/article/id/e53946e2-c6c4-41e9-9a9bfea8db1a8f51. Accessed 27 Feb 2020.

26. Wei M, Yuan J, Liu Y, Fu T, Yu X, Zhang Z-J. Novel coronavirus infection in hospitalized infants under 1 year of age in China. JAMA. 2020. https://doi.org/ 10.1001/jama.2020.2131.

27. Chen H, Guo J, Wang C, et al. Articles Clinical characteristics and intrauterine vertical transmission potential of COVID-19 infection in nine pregnant women: a retrospective review of medical records. Lancet. 2020;395:809-15.

28. WHO. Coronavirus disease (COVID-19) technical guidance: laboratory testing for 2019-nCoV in humans. https://www.who.int/emergencies/ diseases/novel-coronavirus-2019/technical-guid ance/laboratory-guidance. Accessed 13 Mar 2020.

29. ECDC. Case definition for EU surveillance of COVID-19, as of 25 February 2020. https://www. ecdc.europa.eu/en/case-definition-and-europeansurveillance-human-infection-novel-coronavirus2019-ncov. Accessed 28 Feb 2020.

30. Wang W, Xu Y, Gao R et al. Detection of SARS-CoV2 in different types of clinical specimens. JAMA. 2020. https://jamanetwork.com/journals/jama/ fullarticle/2762997. Accessed 12 Mar 2020.

31. CDC. Prevention, treatment of coronavirus disease 2019 (COVID-19)|CDC. https://www.cdc.gov/ coronavirus/2019-ncov/about/preventiontreatment.html. Accessed 28 Feb 2020.

32. Zumla A, Hui DS, Azhar EI, Memish ZA, Maeurer M. Reducing mortality from 2019-nCoV: host-directed therapies should be an option. Lancet. 2020. https://www.thelancet.com/journals/lancet/article/ PIIS0140-6736(20)30305-6/fulltext. Accessed 13 Mar 2020.

33. Harrison C. Coronavirus puts drug repurposing on the fast track. Nat Biotechnol. 2020. https://www. nature.com/articles/d41587-020-00003-1. Accessed 12 Mar 2020.

34. CNHC. Avviso sull'emissione di un nuovo piano di diagnosi e trattamento della polmonite da coronavirus. https://www.nhc.gov.cn/yzygj/s7653p/2020 
03/46c9294a7dfe4cef80dc7f5912eb1989.shtml. Accessed 12 Mar 2020.

35. Alex Philippidis. How to conquer coronavirus: top 35 treatments in development. https://www.geneng news.com/a-lists/how-to-conquer-coronavirus-top35-treatments-in-development/. Accessed 12 Mar 2020 .

36. Efficacy and safety of darunavir and cobicistat for treatment of pneumonia caused by 2019-nCoVfull text view-ClinicalTrials.gov. https:// clinicaltrials.gov/ct2/show/NCT04252274. Accessed 12 Mar 2020.

37. The efficacy of lopinavir plus ritonavir and arbidol against novel coronavirus infection-full text view-ClinicalTrials.gov. https://clinicaltrials.gov/ ct2/show/NCT04252885. Accessed 12 Mar 2020.

38. A randomized, open, controlled clinical study to evaluate the efficacy of ASC09F and ritonavir for 2019-nCoV pneumonia-full text view-ClinicalTrials.gov. https://clinicaltrials.gov/ct2/show/ NCT04261270. Accessed 12 Mar 2020.

39. Chen L, Xiong J, Bao L, Shi Y. Convalescent plasma as a potential therapy for COVID-19. Lancet Infect Dis. 2020. https://doi.org/10.1016/S14733099(20)30141-9.

40. Russell CD, Millar JE, Baillie JK. Clinical evidence does not support corticosteroid treatment for 2019-nCoV lung injury. Lancet. 2020;395:473-5.

41. WHO. Director-General's opening remarks at the media briefing on COVID-19. 2020. https://www. who.int/dg/speeches/detail/who-director-general-sopening-remarks-at-the-media-briefing-on-covid19-11-march-2020. Accessed 12 Mar 2020.
42. Wang C, Horby PW, Hayden FG, Gao GF. A novel coronavirus outbreak of global health concern. Lancet. 2020. https://www.thelancet.com/journals/ lancet/article/PIIS0140-6736(20)30185-9/fulltext. Accessed 30 Jan 2020.

43. WHO. Updated WHO recommendations for international traffic in relation to COVID-19 outbreak. https://www.who.int/news-room/articles-detail/ updated-who-recommendations-for-internationaltraffic-in-relation-to-covid-19-outbreak. Accessed 11 Mar 2020.

44. CDC. COVID-19 information for Travelers|CDC. https://www.cdc.gov/coronavirus/2019-ncov/ travelers/index.html. Accessed 20 Feb 2020.

45. WHO. Infection prevention and control. https:// www.who.int/emergencies/diseases/novel-corona virus-2019/technical-guidance/infection-preventionand-control. Accessed 13 Mar 2020.

46. Gazzetta Ufficiale Della Repubblica Italiana. G.U. Serie Generale n. 62 del 09 marzo 2020. https:// www.trovanorme.salute.gov.it/norme/dettaglioAtto? id=73629. Accessed 10 Mar 2020.

47. Gazzetta Ufficiale della Repubblica Italiana. G.U. Serie Generale , n. 59 del 08 marzo 2020. https:// www.trovanorme.salute.gov.it/norme/dettaglioAtto? $\mathrm{id}=73594$. Accessed 9 Mar 2020.

48. Centro Nazionale Sangue. Nuovo Coronavirus, nuove misure di prevenzione dopo la trasmissione locale|Centro Nazionale Sangue. https://www. centronazionalesangue.it/node/813. Accessed 26 Feb 2020. 